\title{
Métodos para a estimativa do potencial de rendimento da soja durante a ontogenia
}

\author{
João Leonardo Fernandes Pires ${ }^{(1)}$, José Antonio Costa $^{(2)}$, Lisandro Rambo(2) e Felipe Gutheil Ferreira ${ }^{(2)}$
}

\begin{abstract}
(1)Embrapa Trigo, Caixa Postal 451, CEP 99001-970 Passo Fundo, RS. E-mail: pires@cnpt.embrapa.br (2)Universidade Federal do Rio Grande do Sul, Fac. de Agronomia, Av. Bento Gonçalves, no 7712, Caixa Postal 776, CEP 90001-970 Porto Alegre, RS. E-mail: jamc@vortex.ufrgs.br, rambol@ig.com.br, ferreirafg@yahoo.com.br
\end{abstract}

Resumo - O objetivo deste trabalho foi estudar métodos para a estimativa do potencial de rendimento da soja durante a ontogenia. Os experimentos foram realizados em Eldorado do Sul, RS, durante as safras de 1996/1997, 1999/2000 e 2000/2001. Os tratamentos constaram de cinco cultivares de soja, FT-Saray, IAS 5, IAS 4, FT-Abyara e FEPAGRO RS-10. Cinco métodos foram utilizados para estimar o rendimento que seria obtido se todas as estruturas reprodutivas presentes no florescimento e no início do enchimento de grãos, produzissem grãos na maturação. O potencial de rendimento no florescimento e no enchimento de grãos, apresentou alta correlação com o número de flores e estruturas reprodutivas, respectivamente. Verificou-se, também, correspondência entre os métodos. Não houve, na maioria das vezes, correlações significativas entre o potencial, no florescimento e enchimento de grãos, e o rendimento de grãos na maturação. Os métodos estudados constituem ferramentas importantes para o manejo, quando utilizados para comparar o potencial de rendimento durante a ontogenia.

Termos para indexação: Glycine max, componentes do rendimento, mapeamento de plantas, monitoramento de lavouras.

\section{Methods for estimating the soybean potential yield during ontogeny}

\begin{abstract}
The objective of this work was to study methods to estimate the soybean potential yield during ontogeny. The experiments were performed in Eldorado do Sul, RS, during the growing seasons of 1996/1997, 1999/2000 and 2000/2001. The treatments consisted of five soybean cultivars, FT-Saray, IAS 5, IAS 4, FT-Abyara and FEPAGRO RS-10. It was calculated the potential yield of each cultivar, by five methods, in order to estimate the yield that would be obtained if all the reproductive structures during flowering and beginning of pod filling produced grains at the maturity. Potential yield (during flowering and pod filling) presented a high correlation with the number of flowers and reproductive structures, respectively. It was also found a correspondence among the methods. Most of the time, it did not occurred significant correlations between potential (during flowering and pod filling) and the grain yield in maturity. The studied methods are important tools for the management of soybean crops, used to compare the potential yield during ontogeny.
\end{abstract}

Index terms: Glycine max, yield components, plant mapping, field monitoring.

\section{Introdução}

O termo potencial de rendimento tem sido usado de forma indiscriminada para designar desde os resultados de experimentos, até o rendimento que seria obtido em condições tidas como de ausência de limitações.

Para Doorenbos \& Kassan (1979), potencial de rendimento (PR) é definido como a produção de grãos por unidade de área de cultivos bem adaptados às condições climáticas locais, sem limitações de água no solo, nutrientes minerais, e sem competição com plantas daninhas ou danos provocados por pragas e doenças. Se- gundo Evans (1993), PR é o rendimento de uma cultivar, em ambiente ao qual está adaptada, com nutrientes e água não limitantes; com pragas, doenças, plantas daninhas e outros estresses efetivamente controlados.

Considera-se PR, no contexto deste trabalho, o rendimento que a soja obteria se as condições ambientais fossem adequadas, dentro do sistema de cultivo e manejo adotado, possibilitando a fixação máxima das estruturas reprodutivas produzidas e presentes nos estádios avaliados. Tal conceito difere de rendimento potencial (RP) por este representar o potencial genético da cultura, não podendo ser estimado, a menos que se con- 
siga quantificar a contribuição de cada gene da planta para o rendimento de grãos (Pires et al., 2000). Esses conceitos podem ser relacionados ao assunto deste trabalho, pois a estimativa do PR, durante a ontogenia, pode permitir a intervenção na lavoura, durante o ciclo, com aplicação de práticas capazes de minimizar as perdas do PR, obtendo-se maior quantidade de grãos na maturação.

Segundo Landivar (1995), o objetivo do método denominado Mapeamento de Plantas, consiste em avaliar o desempenho das plantas durante o ciclo e selecionar opções de manejo apropriadas, a fim de alcançar metas de crescimento para cada estádio ontogênico. Bourland \& Watson (1990) desenvolveram uma técnica que serviu de base para o mapeamento de plantas, visando a avaliação da estrutura e rendimento das plantas de algodão (COTMAP), o que permite distinguir variações na estrutura e frutificação, associadas a diferenças genéticas, reguladores de crescimento e danos provocados por insetos. Para o algodão, desenvolveu-se também um método que permite a identificação de cada nó da planta e, com isso, a quantificação dos órgãos reprodutivos por região da planta (Bourland \& Watson, 1990; Hake et al., 1993a, 1993b). Este método foi posteriormente adaptado para a cultura da soja, permitindo mapear uma planta de soja em poucos minutos (Keisling \& Counce, 1997).

No Brasil, as primeiras adaptações do método de mapeamento de plantas foram realizadas por Costa (2004), que propôs um método similar para a soja, com o objetivo de fornecer informações que permitam opções de manejo, visando rendimentos elevados. Para tanto, por meio de amostragens, é feita a avaliação do crescimento do caule e ramos, bem como da localização, tipo e quantidade de estruturas reprodutivas durante o desenvolvimento da cultura.

Segundo Costa (1996), um ideótipo desejável de planta de soja, para proporcionar rendimentos elevados, deve reunir: estatura de planta igual ou superior a $0,65 \mathrm{~m}$; inserção dos primeiros legumes superior a $0,10 \mathrm{~m}$; resistência a doenças, insetos, pragas, nematóides, acamamento e deiscência precoce; boa qualidade fisiológica da semente; adaptação às condições locais de ambiente e sistema agrícola; alta capacidade de extração de fósforo; além de tolerância a deficiências e excessos hídricos. Além destas, Egli et al. (1987) ressal- tam a necessidade de se ter $500 \mathrm{~g} \mathrm{~m}^{-2}$ de matéria seca no estádio R5 (início do enchimento de grãos).

Para a identificação de lavouras com maior potencial de rendimento, é necessário que se disponha de práticas eficientes de manejo capazes de intervir nas mesmas. Entre tais práticas, temos a irrigação, o controle de doenças, a aplicação de nitrogênio em cobertura em estádios reprodutivos (Holin, 1997; Lamond \& Wesley, 2001) e controle de pragas. A avaliação intensa da lavoura, com determinação de seu potencial produtivo e aplicação de práticas nos lugares em que possibilitem maior retorno e menor impacto ambiental, é coerente com a idéia de agricultura de precisão e com a busca de sustentabilidade na agricultura.

O objetivo deste trabalho foi avaliar métodos para estimativa do potencial de rendimento da soja, durante a ontogenia, com base na quantidade e qualidade das estruturas reprodutivas.

\section{Material e Métodos}

Realizaram-se três experimentos nos anos: 1996/1997 (I), 1999/2000 (II) e 2000/2001 (III), na Universidade Federal do Rio Grande do Sul em Eldorado do Sul. O solo da área experimental, de acordo com a Embrapa (1999), pertence à unidade de mapeamento São Jerônimo, classificado como Argissolo Vermelho distrófico típico.

O delineamento experimental utilizado foi o de blocos ao acaso, com quatro repetições. Os tratamentos constaram de cinco cultivares de hábito de crescimento determinado, sendo duas de ciclo precoce (FT-Saray e IAS 5), uma de ciclo médio (IAS 4), uma de ciclo semitardio (FT-Abyara) e uma de ciclo tardio (FEPAGRO RS-10), na população de 30 a 40 plantas $\mathrm{m}^{-2}$. As unidades experimentais foram formadas por quatro linhas de $5 \mathrm{~m}$ de comprimento, com espaçamento entre linhas de $0,4 \mathrm{~m}$.

O experimento I foi conduzido em sistema convencional e os experimentos II e III em semeadura direta, com cobertura de aveia preta (3.800 kg ha-1) e aveia mais ervilhaca (5.800 $\left.\mathrm{kg} \mathrm{ha}^{-1}\right)$, respectivamente. A semeadura foi efetuada dentro da época preferencial para o cultivo da soja, manualmente, no experimento I e com semeadora de parcelas, nos experimentos II e III. 
As sementes foram tratadas com fungicida específico e receberam inoculação de Bradyrhizobium japonicum. Foi realizada suplementação hídrica no experimento I, por meio de aspersores fixos. Nos experimentos II e III, não se utilizou suplementação hídrica.

A fim de coletar dados para o cálculo da estimativa do potencial de rendimento, foram utilizadas cinco plantas no experimento I e dez nos experimentos II e III, marcadas em seqüência na linha, no início do ciclo da cultura, estádio V4 - quarto nó -, segundo Costa \& Marchezan (1982).

Realizou-se o cálculo da estimativa do potencial de rendimento (PR) da soja, durante a ontogenia, com base nas estruturas reprodutivas. Foram utilizados cinco métodos, visando estimar o rendimento que seria obtido se todas as estruturas reprodutivas (flores e legumes) presentes em R2 (florescimento) e R5 (início do enchimento de grãos) chegassem à maturação (R8), produzindo grãos. Nesse caso, considera-se que não haveria limitações de assimilados (fonte) para suprir essa demanda (flores e legumes).

Os métodos propostos são apresentados a seguir. O método A utilizou dados obtidos durante o ciclo da cultura e na maturação, como número de flores em R2 e R5, número de legumes em R5, porcentagem de legumes com zero, um, dois e três grãos em R8 e peso de 100 grãos de legumes com um, dois e três grãos em R8. $\mathrm{O}$ método $\mathrm{B}$ utilizou os mesmos dados do método $\mathrm{A}$, excluindo flores em R5 e porcentagem de legumes com zero grãos em R8.

Para o método C, foram coletados dados de flores e legumes, em R2 e R5, e de número de grãos por legume e peso de 100 grãos, característicos de cada cultivar, além de dados disponíveis na literatura (Menezes et al., 1997; Reunião de Pesquisa de Soja da Região Sul, 1997).

O método D utilizou dados coletados em R2 e R5 e valores médios de peso de 100 grãos e número de grãos por legume para todas as cultivares, obtidos na literatura (Menezes et al., 1997; Embrapa, 1997).

Para o método E, coletaram-se dados em R2 e R5, e dados de porcentagem de legumes com um, dois e três grãos, de peso de 100 grãos característicos de cada cultivar e dados disponíveis na literatura (Menezes et al., 1997).

Os cálculos do PR foram efetuados a partir dos dados referentes às características das cultivares, obtidos nas recomendações técnicas da cultura da soja (Embrapa, 1997), relativos ao peso de 100 grãos e porcentagem de legumes com um, dois e três grãos, obtidos por Menezes et al. (1997).

O PR no florescimento pleno (R2) e no início do enchimento de grãos (R5) foi obtido por meio das fórmulas apresentadas a seguir, usando como exemplo o PR em R2:

Método A: PR = \{[(0) . (FR2 . \%L0GR8) . (P1GL0G) $]+$ [(1). (FR2 . \%L1GR8) . (P1GL1G)] + [(2) . (FR2 . \%L2GR8) . (P1GL2G)] + [(3) . (FR2 . \%L3GR8) . (P1GL3G)]\} /10

Método B: PR = \{[(1) . (FR2 . \%L1GR8) . (P1GL1G) $]+$ [(2). (FR2 . \%L2GR8) . (P1GL2G)] + [(3) . (FR2 . \%L3GR8) . (P1GL3G)]\} /10

Método C: $P R=[(G / L C) \cdot($ FR2 $) \cdot(P 1 G C)] \cdot 10$

Método D: $P R=(G / L) \cdot(F R 2) \cdot(P 1 G) \cdot 10$

Método E: PR $=\{[(1) \cdot($ FR2 . \%L1GR8).$(P 1 G C)]+$ [(2) . (FR2 . \%L2GR8) . (P1GC)]+ [(3) . (FR2 . \%L3GR8). (P1GC)] $/ 10$

em que PR é o potencial de rendimento no florescimento $\left(\mathrm{kg} \mathrm{ha}^{-1}\right)$; FR2 é o número de flores $\mathrm{m}^{-2}$ em R2; \%L1GR8, \%L2GR8, \%L3GR8 são as porcentagens de legumes com um, dois ou três grãos em R8; P1GL1G, P1GL2G, P1GL3G são os pesos de um grão de legumes (g) com um, dois ou três grãos, respectivamente, a 13\% de umidade (estimado pelo peso de 100 grãos de legumes com um grão); G/LC é o número de grãos por legume, característico da cultivar; P1GC é o peso de um grão (g) a 13\% de umidade (estimado pelo peso de 100 grãos), característico da cultivar; G/L é o número de grãos por legume das cinco cultivares; P1G é o peso de um grão (g) a 13\% de umidade (estimado pelo peso de 100 grãos) das cinco cultivares. Foram realizados alguns ajustes nas fórmulas (como a divisão por dez) a fim de expressar os resultados em $\mathrm{kg} \mathrm{ha}^{-1}$. A análise estatística foi realizada, primeiramente, com a análise individual dos três anos de experimento. Fezse a análise de variância pelo teste F, bem como, análi- 
se de correlação (utilizando-se o teste t) entre os resultados de PR dos diferentes métodos, rendimento em R8 da amostra (R8a) e rendimento em R8 obtido na área útil da parcela (R8p), nos três anos de realização do experimento. $\mathrm{O}$ aplicativo computacional utilizado para as análises foi o SAS (1987).

\section{Resultados e Discussão}

Os resultados mostraram que o maior PR, em R2, foi de $14.246 \mathrm{~kg} \mathrm{ha}^{-1}$ e em R5, de $12.179 \mathrm{~kg} \mathrm{ha}^{-1}$, na média das cultivares. O maior potencial na média dos métodos foi obtido em 2000/2001 para R2 (13.390 $\mathrm{kg} \mathrm{ha}^{-1}$ ) e em 1999/2000, para R5 (11.135 kg ha-1). Os valores estimados pelos métodos foram bastante similares, com variação de 8,7\% em R2 e 13,9\% em R5, entre o menor e maior valor, na média dos três anos. Observou-se também que o método E, que usa dados da literatura, apresentou os maiores valores estimados (numericamente), tanto em R2 quanto em R5, na média dos três anos (Tabela 1).

As análises realizadas entre os métodos de cálculo mostraram alta associação entre os mesmos, tanto em

Tabela 1. Potencial de rendimento da soja no florescimento (R2) e início do enchimento de grãos (R5), estimado por diferentes métodos, e rendimento na maturação (R8) da amostra (R8a) e área útil (R8p), na média de cinco cultivares e três anos agrícolas, 1996/1997, 1999/2000 e 2000/2001.

\begin{tabular}{ccc}
\hline Método & \multicolumn{2}{c}{ Potencial de rendimento $\left(\mathrm{kg} \mathrm{ha}^{-1}\right)$} \\
\cline { 2 - 3 } & $\mathrm{R} 2$ & $\mathrm{R} 5$ \\
\hline $\mathrm{A}$ & 11.912 & 9.538 \\
$\mathrm{~B}$ & 12.846 & 8.885 \\
$\mathrm{C}$ & 12.240 & 9.566 \\
$\mathrm{D}$ & 12.498 & 9.653 \\
E & 12.944 & 10.121 \\
\hline \multicolumn{3}{c}{ Rendimento de grãos $\left(\mathrm{kg} \mathrm{ha}^{-1}\right)$} \\
R8a & 3.848 \\
R8p & 3.726 \\
\hline
\end{tabular}

(1)A: usa dados de flores em R2 e R5, legumes em R5, \% de legumes com zero, um, dois e três grãos em R8 e peso de 100 grãos de legumes com um, dois e três grãos em R8; B: usa dados de flores em R2, legumes em $\mathrm{R} 5$, \% de legumes com um, dois e três grãos em R8 e peso de 100 grãos de legumes com um, dois e três grãos em R8; C: usa dados de flores em R2 e R5, legumes em R5, número de grãos por legume e peso de 100 grãos, ambos característicos de cada cultivar; D: usa dados de flores em R2 e R5, legumes em R5, número médio de grãos por legume das cinco cultivares utilizadas e peso médio de 100 grãos das cinco cultivares; E: usa dados de flores em R2 e R5, legumes em R5, número de legumes com um, dois e três grãos e peso de 100 grãos característico de cada cultivar.
R2 como em R5, em todos os anos. No entanto, nenhum método usado apresentou correlação significativa com o rendimento da amostra e da área útil da parcela (Tabelas 2 e 3).

O método A foi utilizado como padrão, para fazer o acompanhamento da cultura durante todo o ciclo. Constatou-se que os outros métodos apresentaram comportamento similar, evidenciado pelas correlações e valores numéricos apresentados nas Tabelas 1, 2 e 3.

O método A é de difícil aplicação prática para avaliar lavouras, principalmente por usar dados de R8. No entanto, o método é bastante adequado para a pesquisa, por seu grau de detalhamento e possibilidade de acompanhamento dos componentes do rendimento.

O método B descarta flores em R5, por terem maior probabilidade de aborto e perderem a competição por

Tabela 2. Correlações entre as estimativas do potencial de rendimento no florescimento (R2), pelos diferentes métodos estudados, e os rendimentos obtidos na amostra (R8a) e na área útil da parcela (R8p) em soja, nos anos agrícolas de 1996/1997, 1999/2000 e 2000/2001.

\begin{tabular}{cccccccc}
\hline Método $^{(1)}$ & Ano & A & B & C & D & E & R8a \\
\hline B & 1997 & $0,98^{*}$ & 1 & & & & \\
& 2000 & $0,86^{*}$ & 1 & & & & \\
& 2001 & $0,99^{*}$ & 1 & & & & \\
C & 1997 & $0,94^{*}$ & $0,98^{*}$ & 1 & & & \\
& 2000 & $0,99^{*}$ & $0,84^{*}$ & 1 & & & \\
& 2001 & $0,92^{*}$ & $0,95^{*}$ & 1 & & & \\
D & 1997 & $0,91^{*}$ & $0,96^{*}$ & $0,96^{*}$ & 1 & & \\
& 2000 & $0,93^{*}$ & $0,83^{*}$ & $0,95^{*}$ & 1 & & \\
& 2001 & $0,91^{*}$ & $0,92^{*}$ & $0,98^{*}$ & 1 & & \\
E & 1997 & $0,94^{*}$ & $0,97^{*}$ & $0,99^{*}$ & $0,96^{*}$ & 1 & \\
& 2000 & $0,98^{*}$ & $0,84^{*}$ & $0,99^{*}$ & $0,95^{*}$ & 1 & 1 \\
& 2001 & $0,92^{*}$ & $0,95^{*}$ & $0,99^{*}$ & $0,98^{*}$ & 1 & \\
$\mathrm{R} 8 \mathrm{a}$ & 1997 & $-0,12$ & $-0,17$ & $-0,21$ & $-0,18$ & $-0,25$ & 1 \\
& 2000 & 0,12 & 0,27 & 0,05 & 0,14 & 0,07 & 1 \\
& 2001 & 0,32 & 0,28 & 0,18 & 0,15 & 0,20 & 1 \\
$\mathrm{R} 8 \mathrm{p}$ & 1997 & $-0,08$ & $-0,013$ & $-0,08$ & 0,10 & $-0,08$ & 0,21 \\
& 2000 & 0,17 & 0,0015 & 0,17 & 0,095 & 0,21 & 0,03 \\
& 2001 & $-0,16$ & $-0,19$ & $-0,28$ & $-0,37$ & $-0,27$ & 0,19 \\
\hline
\end{tabular}

(1)A: usa dados de flores em R2 e R5, legumes em R5, \% de legumes com zero, um, dois e três grãos em R8 e peso de 100 grãos de legumes com um, dois e três grãos em R8; B: usa dados de flores em R2, legumes em R5, \% de legumes com um, dois e três grãos em R8 e peso de 100 grãos de legumes com um, dois e três grãos em R8; C: usa dados de flores em R2 e R5, legumes em R5, número de grãos por legume e peso de 100 grãos, ambos característicos de cada cultivar; D: usa dados de flores em R2 e R5, legumes em R5, número médio de grãos por legume das cinco cultivares utilizadas e peso médio de 100 grãos das cinco cultivares; E: usa dados de flores em R2 e R5, legumes em R5, número de legumes com um, dois e três grãos e peso de 100 grãos característico de cada cultivar. *Significativo a $5 \%$ de probabilidade pelo teste t. 
assimilados com legumes e grãos, que têm maior força de demanda. Legumes sem grãos, em R8, foram eliminados por apresentarem grande variação (dentro de um mesmo tratamento) e serem de difícil quantificação, por conta da elevada perda na colheita e no manuseio das amostras. Os resultados obtidos com este método demonstraram que estas estruturas não trazem maior precisão na estimativa, pois, sem sua quantificação, obtêmse resultados semelhantes aos de outros métodos (Tabela 1).

O método C, tido como próprio para utilização em lavouras, e por não necessitar de dados de R8, pode proporcionar uma estimativa em tempo real do potencial de rendimento, pois usa dados coletados em R2 e R5, além de dados disponíveis na literatura.

O método D buscou representar diretamente os valores de flores e legumes presentes durante a ontogenia.

Tabela 3. Correlações entre as estimativas do potencial de rendimento no início do enchimento de grãos (R5), pelos diferentes métodos estudados, e os rendimentos obtidos na amostra (R8a) e na área útil da parcela (R8p) em soja, nos anos agrícolas de 1996/1997, 1999/2000 e 2000/2001.

\begin{tabular}{cccccccr}
\hline Método $^{(1)}$ & Ano & A & B & C & D & E & R8a \\
\hline B & 1997 & $0,80^{*}$ & 1 & & & & \\
& 2000 & $0,93^{*}$ & 1 & & & & \\
& 2001 & $0,92^{*}$ & 1 & & & & \\
$\mathrm{C}$ & 1997 & $0,94^{*}$ & $0,87^{*}$ & 1 & & & \\
& 2000 & $0,90^{*}$ & $0,93^{*}$ & 1 & & & \\
& 2001 & $0,87^{*}$ & $0,90^{*}$ & 1 & & & \\
$\mathrm{D}$ & 1997 & $0,88^{*}$ & $0,90^{*}$ & $0,96^{*}$ & 1 & & \\
& 2000 & $0,82^{*}$ & $0,89^{*}$ & $0,95^{*}$ & 1 & & \\
& 2001 & $0,76^{*}$ & $0,78^{*}$ & $0,88^{*}$ & 1 & & \\
$\mathrm{E}$ & 1997 & $0,93^{*}$ & $0,88^{*}$ & $0,99^{*}$ & $0,97^{*}$ & 1 & \\
& 2000 & $0,90^{*}$ & $0,94^{*}$ & $0,99^{*}$ & $0,96^{*}$ & 1 & \\
& 2001 & $0,85^{*}$ & $0,88^{*}$ & $0,98^{*}$ & $0,87^{*}$ & 1 & \\
$\mathrm{R} 8 \mathrm{a}$ & 1997 & $-0,05$ & $-0,21$ & $-0,16$ & $-0,15$ & $-0,17$ & 1 \\
& 2000 & 0,11 & 0,20 & 0,16 & 0,26 & 0,18 & 1 \\
& 2001 & $0,57^{*}$ & $0,48^{*}$ & $0,44^{*}$ & $0,44^{*}$ & $0,47 *$ & 1 \\
$\mathrm{R} 8 \mathrm{p}$ & 1997 & $-0,37^{*}$ & $-0,24$ & $-0,35$ & $-0,19$ & $-0,35$ & 0,21 \\
& 2000 & 0,22 & 0,28 & 0,22 & 0,13 & 0,24 & 0,03 \\
& 2001 & 0,18 & 0,012 & 0,05 & $-0,24$ & 0,05 & 0,19 \\
\hline
\end{tabular}

${ }^{(1)} \mathrm{A}$ : usa dados de flores em R2 e R5, legumes em R5, \% de legumes com zero, um, dois e três grãos em R8 e peso de 100 grãos de legumes com um, dois e três grãos em R8; B: usa dados de flores em R2, legumes em R5, \% de legumes com um, dois e três grãos em R8 e peso de 100 grãos de legumes com um, dois e três grãos em R8; C: usa dados de flores em R2 e R5, legumes em R5, número de grãos por legume e peso de 100 grãos, ambos característicos de cada cultivar; D: usa dados de flores em R2 e R5, legumes em R5, número médio de grãos por legume das cinco cultivares utilizadas no estudo e peso médio de 100 grãos das cinco cultivares; E: usa dados de flores em R2 e R5, legumes em R5, número de legumes com um, dois e três grãos e peso de 100 grãos característico de cada cultivar. *Significativo a 5\% de probabilidade pelo teste t.
O método E objetivou verificar se dados relatados na literatura seriam similares aos obtidos no presente estudo e, de certa forma, avaliar o comportamento das cultivares em situações distintas (Tabela 1).

Os componentes do número de flores $\mathrm{m}^{-2}$, em R2, e número de estruturas $\mathrm{m}^{-2}$ (flores + legumes), em R5, mostraram correlações positivas e significativas com PR, nos três anos avaliados. Os demais componentes não apresentaram fortes correlações com PR, a não ser em alguns anos e, geralmente, negativas (Tabelas 4 e 5).

As características avaliadas tiveram pouca associação com o rendimento em R8 (da amostra e da parcela). Somente o peso de 100 grãos, durante o ano 2001, mostrou relação consistente com o rendimento da parcela, embora não suficiente para indicar esta característica como altamente determinante do PR em R2 (Tabela 4).

Os resultados evidenciam que os métodos propostos são importantes, quando utilizados para comparar situações distintas (lavouras, práticas de manejo e tratamentos experimentais), mas têm pouca precisão na predição de rendimentos.

Trabalhos que utilizaram o método A, realizados por Ventimiglia et al. (1999), Pires et al. (2000), Navarro Junior \& Costa (2002), Maehler et al. (2003) e Rambo et al. (2004), obtiveram PR máximo de $22.200 \mathrm{~kg} \mathrm{ha}^{-1}$ em R2 e $14.976 \mathrm{~kg} \mathrm{ha}^{-1}$ em R5 (em tratamentos isolados), trabalhando com diferentes níveis de fertilidade, irrigação, espaçamentos entre linhas, populações de plantas e cultivares.

Segundo Ventimiglia et al. (1999), a deficiência de fósforo no solo diminuiu o PR nos estádios reprodutivos iniciais, pela menor produção de flores e maior aborto destas estruturas, continuando a se manifestar com menor produção de legumes e maior abscisão destes.

Para Pires et al. (2000), tanto a população quanto o espaçamento entre linhas afetam o PR durante a ontogenia. Com uso de espaçamento reduzido $(20 \mathrm{~cm})$, é possível reduzir a perda de potencial a partir de R5 (em comparação a $40 \mathrm{~cm}$ ), resultando em maior rendi- 
mento em R8. No entanto, o uso de população de 40 plantas $\mathrm{m}^{-2}$, embora aumente o potencial durante a ontogenia, não garante maior rendimento em R8, em relação a 30 plantas $\mathrm{m}^{-2}$.

Navarro Junior \& Costa (2002) demonstraram, também, variação no PR entre cultivares de soja durante a ontogenia. No entanto, como mostrado neste trabalho, a maior produção de flores não garante rendimento elevado em R8; o fato de a cultivar apresentar alta produção de flores não identifica uma cultivar eficiente na fixação destas flores.

A irrigação é outra prática que aumenta o PR, pela maior produção e fixação de flores e legumes. Cultivares como BRS 137 apresentam maior potencial que BRS 138 em R2, decorrente do menor aborto de flores e abscisão de legumes, o que resulta em maior rendimento em R8 (Maehler et al., 2003).
Verifica-se, nas Tabelas 2 e 3 que os métodos têm baixa correlação com o rendimento em R8, pois sabese que existem inúmeros fatores que afetam as estruturas reprodutivas, após a determinação do potencial.

No entanto, a estimativa do PR, neste trabalho, deve ser analisada de acordo com os conceitos propostos, que reforçam a teoria da quantificação do potencial em tempo real, para a aplicação de práticas de manejo, capazes de minimizar sua perda.

Dentro desse contexto, a capacidade preditiva da estimativa fica em segundo plano, pois muitos fatores podem afetar este potencial depois de sua quantificação. Entretanto, alguns trabalhos demonstram que diferenças proporcionadas por práticas de manejo diferenciadas, no PR estimado em R2, R4 e R5, em algumas situações, são mantidas até a maturação, resultando em maior rendimento de grãos (Ventimiglia et al., 1999; Pires et al., 2000; Maehler et al., 2003).

Tabela 4. Correlações entre os componentes usados para estimar o potencial de rendimento no florescimento (R2) e o potencial calculado por diferentes métodos estudados e os rendimentos obtidos na amostra (R8a) e na área útil da parcela (R8p) em soja, nos anos agrícolas de 1996/1997, 1999/2000 e 2000/2001(1).

\begin{tabular}{|c|c|c|c|c|c|c|c|c|c|c|}
\hline Método $^{(2)}$ & Ano & Flores & Estruturas & $\begin{array}{c}\text { P100 } \\
\text { (1 grão) }\end{array}$ & $\begin{array}{c}\text { P100 } \\
\text { (2 grãos) }\end{array}$ & $\begin{array}{c}\text { P100 } \\
\text { (3 grãos) }\end{array}$ & $\begin{array}{c}\text { L0G } \\
(\%)\end{array}$ & $\begin{array}{l}\mathrm{L} 1 \mathrm{G} \\
(\%)\end{array}$ & $\begin{array}{l}\mathrm{L} 2 \mathrm{G} \\
(\%)\end{array}$ & $\begin{array}{l}\mathrm{L} 3 \mathrm{G} \\
(\%)\end{array}$ \\
\hline \multirow[t]{3}{*}{ A } & 1997 & $0,91 *$ & $0,72 *$ & $-0,36$ & $-0,19$ & $-0,11$ & 0,09 & $-0,19$ & $-0,08$ & 0,13 \\
\hline & 2000 & $0,93 *$ & $0,37 *$ & 0,12 & 0,11 & 0,21 & 0,01 & 0,25 & 0,16 & $-0,23$ \\
\hline & 2001 & $0,91 *$ & $0,53 *$ & 0,01 & $-0,19$ & $-0,11$ & $-0,32$ & 0,36 & $-0,52 *$ & $0,50^{*}$ \\
\hline \multirow[t]{3}{*}{ B } & 1997 & $0,96^{*}$ & $0,73^{*}$ & $-0,47^{*}$ & $-0,31$ & $-0,21$ & 0,27 & $-0,26$ & $-0,19$ & 0,18 \\
\hline & 2000 & $0,83^{*}$ & 0,28 & $-0,06$ & $-0,04$ & 0,08 & 0,10 & 0,12 & 0,06 & $-0,10$ \\
\hline & 2001 & $0,92 *$ & $0,53 *$ & $-0,04$ & $-0,22$ & $-0,16$ & $-0,20$ & 0,30 & $-0,57^{*}$ & $0,54^{*}$ \\
\hline \multirow[t]{3}{*}{$\mathrm{C}$} & 1997 & $0,96^{*}$ & $0,80 *$ & $-0,50 *$ & $-0,33$ & $-0,22$ & 0,34 & $-0,26$ & $-0,23$ & 0,18 \\
\hline & 2000 & $0,95^{*}$ & 0,37 & 0,10 & 0,07 & 0,15 & 0,01 & 0,26 & 0,15 & $-0,22$ \\
\hline & 2001 & $0,98^{*}$ & $0,60 *$ & $-0,21$ & $-0,39$ & $-0,34$ & $-0,08$ & 0,32 & $-0,57^{*}$ & $0,49 *$ \\
\hline \multirow[t]{3}{*}{$\mathrm{D}$} & 1997 & $1,00 *$ & $0,68 *$ & $-0,63^{*}$ & $-0,50 *$ & $-0,41$ & 0,43 & $-0,33$ & $-0,33$ & 0,26 \\
\hline & 2000 & $1,00^{*}$ & 0,30 & $-0,14$ & $-0,20$ & $-0,10$ & 0,08 & 0,11 & $-0,003$ & $-0,06$ \\
\hline & 2001 & $1,00^{*}$ & $0,54 *$ & $-0,33$ & $-0,52^{*}$ & $-0,47 *$ & $-0,10$ & 0,32 & $-0,62 *$ & $0,55^{*}$ \\
\hline \multirow[t]{3}{*}{$\mathrm{E}$} & 1997 & $0,96 *$ & $0,80 *$ & $-0,54^{*}$ & $-0,38$ & $-0,27$ & 0,36 & $-0,32$ & $-0,28$ & $-0,24$ \\
\hline & 2000 & $0,95^{*}$ & $0,41^{*}$ & 0,06 & 0,03 & 0,13 & $-0,01$ & 0,22 & 0,11 & $-0,17$ \\
\hline & 2001 & $0,98 *$ & $0,58 *$ & $-0,22$ & $-0,39$ & $-0,36$ & $-0,02$ & 0,28 & $-0,61 *$ & $0,53 *$ \\
\hline \multirow[t]{3}{*}{$\mathrm{R} 8 \mathrm{a}$} & 1997 & $-0,18$ & $-0,15$ & 0,08 & 0,06 & $-0,01$ & $-0,26$ & $-0,06$ & 0,32 & $-0,13$ \\
\hline & 2000 & 0,14 & 0,17 & $-0,02$ & $-0,11$ & $-0,13$ & 0,29 & $-0,16$ & $-0,19$ & 0,17 \\
\hline & 2001 & 0,15 & $0,44^{*}$ & 0,25 & 0,17 & 0,25 & $-0,32$ & 0,30 & $-0,002$ & 0,01 \\
\hline \multirow[t]{3}{*}{$\mathrm{R} 8 \mathrm{p}$} & 1997 & 0,10 & $-0,20$ & $-0,26$ & $-0,30$ & $-0,35$ & $-0,17$ & $-0,16$ & $-0,09$ & 0,08 \\
\hline & 2000 & 0,09 & 0,23 & 0,05 & 0,11 & 0,18 & $-0,12$ & $-0,05$ & $-0,06$ & 0,07 \\
\hline & 2001 & $-0,37$ & $-0,24$ & $0,70^{*}$ & $0,71 *$ & $0,69 *$ & $-0,27$ & 0,33 & $0,59 *$ & $-0,60$ * \\
\hline
\end{tabular}

(1)P 100: peso de 100 grãos (13\% de umidade) de legumes com 1, 2 e 3 grãos; L0G: legume com zero grão; L1G: legume com um grão; L2G: legume com dois grãos; L3G: legume com três grãos; estruturas: flores + legumes. ${ }^{(2)}$ A: usa dados de flores em R2 e R5, legumes em R5, \% de legumes com zero, um, dois e três grãos em R8 e peso de 100 grãos de legumes com um, dois e três grãos em R8; B: usa dados de flores em R2, legumes em R5, \% de legumes com um, dois e três grãos em R8 e peso de 100 grãos de legumes com um, dois e três grãos em R8; C: usa dados de flores em R2 e R5, legumes em R5, número de grãos por legume e peso de 100 grãos, ambos característicos de cada cultivar; D: usa dados de flores em R2 e R5, legumes em R5, número médio de grãos por legume das cinco cultivares utilizadas no estudo e peso médio de 100 grãos das cinco cultivares; E: usa dados de flores em R2 e R5, legumes em R5, número de legumes com um, dois e três grãos e peso de 100 grãos característico de cada cultivar. *Significativo a $5 \%$ de probabilidade pelo teste $\mathrm{t}$. 
Tabela 5. Correlações entre os componentes usados para estimar o potencial de rendimento no início do enchimento de grãos (R5) e o potencial calculado por diferentes métodos e os rendimentos obtidos na amostra (R8a) e na área útil da parcela (R8p) em soja, nos anos agrícolas de 1996/1997, 1999/2000 e 2000/2001(1).

\begin{tabular}{ccccccccccc}
\hline Método $^{(2)}$ & Ano & Flores & Estruturas & $\begin{array}{c}\text { P100 } \\
(1 \text { grão })\end{array}$ & $\begin{array}{c}\text { P100 } \\
(2 \text { grãos })\end{array}$ & $\begin{array}{c}\text { P100 } \\
(3 \text { grãos })\end{array}$ & $\begin{array}{r}\text { L0G } \\
(\%)\end{array}$ & $\begin{array}{c}\text { L1G } \\
(\%)\end{array}$ & $\begin{array}{c}\text { L2G } \\
(\%)\end{array}$ & $\begin{array}{c}\text { L3G } \\
(\%)\end{array}$ \\
\hline \multirow{2}{*}{$\mathrm{A}$} & 1997 & $0,88^{*}$ & $0,69^{*}$ & 0,01 & 0,19 & 0,28 & $-0,27$ & $-0,06$ & 0,29 & $-0,01$ \\
& 2000 & $0,89^{*}$ & $0,81^{*}$ & 0,39 & 0,40 & 0,33 & $-0,47$ & 0,14 & 0,16 & $-0,13$ \\
& 2001 & $0,76^{*}$ & $0,63^{*}$ & $0,55^{*}$ & 0,39 & $0,49^{*}$ & $-0,37$ & 0,17 & 0,14 & $-0,09$ \\
B & 1997 & $0,90^{*}$ & $0,97^{*}$ & $-0,23$ & $-0,18$ & $-0,01$ & 0,13 & $-0,30$ & 0,03 & 0,06 \\
& 2000 & $0,95^{*}$ & $0,93^{*}$ & 0,37 & 0,34 & 0,24 & $-0,48$ & 0,16 & 0,09 & $-0,10$ \\
& 2001 & $0,78^{*}$ & $0,80^{*}$ & 0,39 & 0,27 & 0,32 & $-0,21$ & 0,07 & 0,003 & 0,04 \\
C & 1997 & $0,96^{*}$ & $0,82^{*}$ & $-0,16$ & 0,01 & 0,14 & 0,04 & $-0,15$ & $-0,10$ & $-0,03$ \\
& 2000 & $0,89^{*}$ & $0,85^{*}$ & 0,43 & 0,41 & 0,34 & $-0,45^{*}$ & 0,32 & 0,21 & $-0,25$ \\
& 2001 & $0,88^{*}$ & $0,79^{*}$ & 0,29 & 0,17 & 0,24 & $-0,05$ & 0,08 & 0,13 & $-0,14$ \\
D & 1997 & $1,00^{*}$ & $0,89^{*}$ & $-0,35$ & $-0,20$ & $-0,06$ & 0,15 & $-0,27$ & 0,01 & 0,06 \\
& 2000 & $1,00^{*}$ & $0,90^{*}$ & 0,22 & 0,18 & 0,12 & $-0,44$ & 0,20 & 0,04 & $-0,09$ \\
& 2001 & $1,00^{*}$ & $0,91^{*}$ & $-0,03$ & $-0,23$ & $-0,11$ & $-0,10$ & 0,14 & $-0,15$ & 0,13 \\
E & 1997 & $0,97^{*}$ & $0,83^{*}$ & $-0,21$ & $-0,04$ & 0,09 & 0,07 & $-0,20$ & $-0,05$ & 0,03 \\
& 2000 & $0,91^{*}$ & $0,87^{*}$ & 0,39 & 0,37 & 0,32 & $-0,46 *$ & 0,28 & 0,16 & $-0,20$ \\
& 2001 & $0,87^{*}$ & $0,77^{*}$ & 0,27 & 0,15 & 0,21 & $-0,03$ & 0,02 & 0,05 & $-0,07$ \\
R8a & 1997 & $-0,18$ & $-0,15$ & 0,08 & 0,06 & $-0,01$ & $-0,26$ & $-0,06$ & 0,32 & $-0,13$ \\
& 2000 & 0,14 & 0,17 & $-0,02$ & $-0,11$ & $-0,13$ & 0,29 & $-0,16$ & $-0,19$ & 0,17 \\
& 2001 & 0,15 & 0,44 & 0,25 & 0,17 & 0,25 & $-0,32$ & 0,30 & $-0,002$ & 0,01 \\
R8p & 1997 & 0,10 & $-0,20$ & $-0,26$ & $-0,30$ & $-0,35$ & $-0,17$ & $-0,16$ & $-0,09$ & 0,08 \\
& 2000 & 0,09 & 0,23 & 0,05 & 0,11 & 0,18 & $-0,12$ & $-0,05$ & $-0,06$ & 0,07 \\
& 2001 & $-0,37$ & $-0,24$ & 0,70 & 0,71 & 0,69 & $-0,27$ & 0,33 & 0,59 & $-0,60$ \\
\hline
\end{tabular}

(1)P 100: peso de 100 grãos (13\% de umidade) de legumes com 1, 2 e 3 grãos; L0G: legume com zero grão; L1G: legume com um grão; L2G: legume com dois grãos; L3G: legume com três grãos; estruturas: flores + legumes. ${ }^{(2)} \mathrm{A}$ : usa dados de flores em R2 e R5, legumes em R5, \% de legumes com zero, um, dois e três grãos em R8 e peso de 100 grãos de legumes com um, dois e três grãos em R8; B: usa dados de flores em R2, legumes em R5, \% de legumes com um, dois e três grãos em R8 e peso de 100 grãos de legumes com um, dois e três grãos em R8; C: usa dados de flores em R2 e R5, legumes em R5, número de grãos por legume e peso de 100 grãos, ambos característicos de cada cultivar; D: usa dados de flores em R2 e R5, legumes em R5, número médio de grãos por legume das cinco cultivares utilizadas no estudo e peso médio de 100 grãos das cinco cultivares; E: usa dados de flores em R2 e R5, legumes em R5, número de legumes com um, dois e três grãos e peso de 100 grãos característico de cada cultivar. *Significativo a $5 \%$ de probabilidade pelo teste $t$.

\section{Conclusões}

1. Os métodos estudados são importantes ferramentas para o manejo, quando utilizados na comparação do potencial de rendimento durante a ontogenia.

2. Os métodos avaliados apresentam semelhanças nas estimativas do potencial de rendimento.

3. As características avaliadas são importantes, para comparar o potencial de rendimento, durante a ontogenia, mas não apresentam associação com o rendimento de grãos em R8.

\section{Referências}

BOURLAND, F.M.; WATSON JUNIOR, C.E. COTMAP, a technique for evaluating structure and yield of cotton plants. Crop Science, v.30, p.224-226, 1990.

COSTA, J.A. Cultura da soja. Porto Alegre: Ed. do autor, 1996. 233p.

COSTA, J.A. Produtividade potencial da soja: mapeamento de plantas. In: CONGRESSO BRASILEIRO DE SOJA, 3., 2004, Foz do Iguaçu. Proceedings. Passo Fundo: Embrapa Soja, 2004. p.12551262.

COSTA, J.A.; MARCHEZAN, E. Características dos estádios de desenvolvimento da soja. Campinas: Fundação Cargil, 1982. 30p.

DOORENBOS, J.; KASSAN, A.H. Yield response to water. Rome: FAO, 1979. 193p. (FAO Irrigation and Drainage Paper, 33).

EGLI, D.B.; GUFFY, R.B.; HEITHOLD, J.J. Factors associated with reduced yields of delayed planting of soybeans. Journal of Agronomy and Crop Science, v.159, p.176-185, 1987.

EMBRAPA. Centro Nacional de Pesquisa de Soja (Londrina, PR). Recomendações Técnicas para a cultura da soja no Rio Grande do Sul e em Santa Catarina, 1997/98. In: Reunião de Pesquisa de Soja da Região Sul, 25., 1997, Passo Fundo. Passo Fundo: EmbrapaCNPSo, 1997. 130p.

EMBRAPA. Centro Nacional de Pesquisa de Solos (Rio de Janeiro, RJ). Sistema brasileiro de classificação de solos. Brasília: Embrapa-CNPS, 1999. 412p.

EVANS, L.T. Processes, genes, and yield potential. In: BUXTON, D.R.; SHIBLES, R.; FORSBERG, R.A.; BLAD, B.L.; ASAY, K.H.; 
PAUSEN, G.M.; WILSON, R.F. (Ed.). International crop science I. Madison: Crop Science Society of America, 1993. 895p.

HAKE, K.; BOURLAND, F.; KERBY, T. Applied plant map handbook: early season management. Memphis: National Cotton Council of America, 1993a. 9p.

HAKE, K.; KERBY, T.; BOURLAND, F.; JEHKINS, J. Beginning plant map program. Memphis: National Cotton Council of America, 1993b. 14p.

HOLIN, F. Midseason N boosts soybean yield. Soybean Digest, v.57, p.6-7, 1997.

KEISLING, T.C.; COUNCE, P.A. An encoding process for morphological analysis of soybean fruit distribution. Crop Science, v.37, p.1665-1669, 1997.

LAMOND, R.E.; WESLEY, T.L. In-season fertilization for high yield soybean production. Better Crops With Plant Food, v.85, p.6-11, 2001.

LANDIVAR, J.A. Monitoring system for the management of cotton crops during ontogeny. Corpus Christi, TA: Texas A \& M University, 1995. 25p.

MAEHLER, A.R.; PIRES, J.L.F.; COSTA, J.A.; FERREIRA, F.G. Potencial de rendimento da soja durante a ontogenia em razão da irrigação e arranjo de plantas. Pesquisa Agropecuária Brasileira, v.38, p.225-231, 2003.

MENEZES, N.L. de; GARCIA, D.C.; RUBIN, S. de A.L.; BERNARDI, G.E. Caracterização de vagens e sementes de soja. Ciência Rural, v.27, p.387-391, 1997.

NAVARRO JÚNIOR, H.M.; COSTA, J.A. Expressão do potencial de rendimento de cultivares de soja. Pesquisa Agropecuária Brasileira, v.37, p.275-279, 2002.

PIRES, J.L.F.; COSTA, J.A.; THOMAS, A.L.; MAEHLER, A.R. Efeito de populações e espaçamentos sobre o potencial de rendimento da soja durante a ontogenia. Pesquisa Agropecuária Brasileira, v.35, p.1541-1547, 2000.

RAMBO, L.; COSTA, J.A.; PIRES, J.L.F.; PARCIANELLO, G.; FERREIRA, F.G. Estimativa do potencial de rendimento por estrato do dossel da soja, em diferentes arranjos de plantas. Ciência Rural, v.34, p.33-40, 2004.

SAS INSTITUTE (Cary, Estados Unidos). SAS/STAT guide for personal computers. Cary: SAS Institute, 1987.

VENTIMIGLIA, L.A.; COSTA, J.A.; THOMAS, A.L.; PIRES, J.L.F. Potencial de rendimento da soja em razão da disponibilidade de fósforo no solo e dos espaçamentos. Pesquisa Agropecuária Brasileira, v.34, p.195-199, 1999.

Recebido em 28 de janeiro de 2004 e aprovado em 22 de novembro de 2004 